\title{
Technological infrastructure and human culture: Appropriating innovative teaching methods to 21st century classrooms
}

\author{
Chong $\mathrm{Su} \mathrm{Li}^{1, *}$ and Roselind $\mathrm{Wan}^{1}$ \\ ${ }^{1}$ Department of Management and Humanities, Universiti Teknologi PETRONAS, Seri Iskandar, \\ 32610 Perak Malaysia
}

\begin{abstract}
Often, it is assumed that the introduction of technological infrastructures into the 21 st century classroom will provide the catalyst to appropriating innovative methods befitting modern educational frameworks. One of these appropriations is the introduction of technology like wireless connectivity, interactive smartboards and mobile devices in the shift from applying teacher-centredness to student-centredness in the classroom. However, this shift is often discussed in terms of technological infrastructure, to the exclusion of examining the cultural change that occurs as a result. This paper discusses findings from a study which set out to examine the effectiveness of electronic marginalia (e-marginalia) in a university classroom for Academic Writing, with e-marginalia being regarded as a technological infrastructure. Drawing from principles of Action Research, this study adopted a constructivist perspective which framed its research design. In the course of 14 weeks, 2 groups of 25 Engineering and Technology undergraduates respectively, underwent draftwriting through the use of Microsoft ${ }^{\circledR}$ track-change function and e-mail communication with two lecturers. This method of classroom and online engagement tested the extent to which infrastructure and human culture could align in a writing course. Data was also drawn from students and lecturers' feedback with regards to their 14-week experience of learning and teaching through new methods. Findings from this study show that when human culture and behaviour is considered, technological infrastructure can be capitalised through the cultural appropriation of human-relationship-sustenance and technological-content-identification. These findings answer the question of teacher-relevance in the Education 4.0 framework. Thus, not only are teachers still very relevant to current pedagogies, it is their sociocultural sensitivities that are tested and confronted. As such, in accommodating new ways of teaching and learning that must chime with Education 4.0, this paper advocates for new forms of openness in 21 st century education.
\end{abstract}

\footnotetext{
*Corresponding author: chong_suli@utp.edu.my
} 


\section{Background of research}

Much is being debated about how educational experience will alter as transformation is expected to take place in the educational landscape, worldwide. In the 21 st century, digital technology is considered to be one of the main drivers undergirding this transformation. Thus, in answering the clarion call of Industrial Revolution 4.0, academics and educationists have chimed in through the Education 4.0 framework so as to think about and prepare for the shift in educational matters.

One of the main dilemmas in confronting educational transformations in the era of 4.0 is the question of whether teachers or lecturers may be replaced. This comes in light of new advances in technology which allows for the democratisation of teaching materials and methodology. Massive open online courses (MOOCS) for example has transformed the way we understand the physical classroom and face-to-face teaching. In allowing for learners to learn from anywhere, MOOCS' philosophy has reduced or completely done away with the face-to-face component. This raises the question of whether human communication may become indispensable in 21 st century classrooms.

This paper raises the question of how educators can appropriate innovative teaching methods which account for both the advantage of technological infrastructure and the indispensability of human communication. This question is particularly pertinent within the field of engineering education where there appears to be a shift from teacher-centred teaching to student-centred learning. In this paper, this question is set within the context of how Academic Writing for undergraduate students in an Engineering and Technological university can be optimised in the current context that assumes that digital technology plays an integral part in the pedagogical process. This paper is a follow on from a previous study that also examined Academic Writing but through the pedagogy of Active Learning (Chong, 2017). As such, this current project sets out to gauge the effectiveness of the use of electronic marginalia (e-marginalia) for the draft writing process in Academic Writing. The significance of this research lay in documenting the response of the students and lecturers who engaged in the use of electronic marginalia across one semester. The research question for this project is: How do undergraduates and lecturers, engaged in the use of electronic marginalia, experience the draft writing process? This paper highlights the lecturers and students' emergent perspectives in order to understand how student-lecturer communication occurs within an educational setting that is supported by technological infrastructure.

\section{Selected literature}

\subsection{Teacher-centred teaching and student-centred learning}

The move from teacher-centred teaching to student-centred learning has been present in the field of Social Science for more than a century. Believed to have mainly begun with the work of educational philosopher John Dewey, this movement became popularised at the latter part of the 20th century. This has been largely due to the human rights movement that strove to locate the child at the heart of educational efforts thus providing the child with equal opportunities to not only learn but more importantly, to develop and thrive (Bromley, Meyer, \& Ramirez, 2011).

Although it initially took root in the field of Social Science, this pedagogy of studentcentredness gained ground in the field of Science education. Particularly, the academic field of Engineering pedagogy found this school of thought to be relevant in the latter decades of 
the 20th century. An initial drop in interest among potential engineering students and a major shift in the way science was understood within the Engineering profession meant that universities dedicated to training and shaping future engineers had to re-think the way they taught their courses. This had a positive impact on the field of Science, Technology, Engineering and Mathematics (STEM) because it encouraged educationists to think about how school and university students approached these subjects especially among learners in the early stages of their education experience (Clements \& Sarama, 2016). One of the outcomes of this re-thinking is the understanding that STEM subjects is as much about hard science as it is about the softer side of learning, negotiating and communicating scientific knowledge (Dejarnette, 2012).

Another important outcome of this approach is the teaching fraternity's sensitivity towards an increasingly culturally-diverse student body across Engineering faculties, worldwide (Committee on the Engineer of 2020 National Academy of Engineering, 2005; Pretz, 2016). However, this shift has raised important questions about whether teacher-centred teaching and student-centred learning are necessarily dichotomous. The Engineering Education fraternity has not been able to agree on such differing paradigms which tend to pit the objectivist/post-positivist perspective against the subjectivist/constructivist perspective (Felder, 2011). The unexpected outcome of such thinking is an imbalanced view which imagines the teacher teaching in silo, or the student learning in silo. In arguing for middle ground, Mascolo (2009) suggests that the teaching and learning process is a constantly iterative and dynamic phenomenon. Even if student-centredness as a philosophy is applied to classroom teaching, the pedagogy is still based on the fundamental logic of what is called "guided participation". In other words, the role of the teacher is still critical to the success of the lesson. However, the efficacy of the lesson is based largely on "(T)he discursive use of language... between teachers and students (which) is a key aspect of the developmental process" (Mascolo, 2009, p. 15). In other words, how the teacher plans and carries out the lessons will shape how independently the students can develop. The title is set in bold 16-point Arial, justified. The first letter of the title should be capitalised with the rest in lower case. You should leave $22 \mathrm{~mm}$ of space above the title and $6 \mathrm{~mm}$ after the title.

\subsection{Teaching of writing to Engineering and Technology undergraduates}

In the present time, we see that student-centred learning has been applied to many Engineering and Technology-based courses that focus on technical knowledge. However, in the Engineering fraternity, there also exists courses that are not technically substantive but yet, revolve around technically substantive content. One example of this subject is Academic Writing. Because of its position as being outside the circle of technical courses, less focus tends to be given to writing (Chong, 2017). This then has brought about a gap in terms of writing-readiness amongst Engineering undergraduates. Jenkins, Jordan, and Weiland (1993) for example, investigated the writing-readiness of postgraduate engineering students in selected engineering faculties in America and found that they were far from ready. One of the main reasons was because their previous training at undergraduate level was insufficient when it came to Academic or Technical Writing. On top of this, language pedagogy lecturers also found that in some cases, the issue was not with writing, but "thinking" (Jenkins et al., 1993, p. 63). This meant that what was initially understood as 'writing challenges' was in fact, a complex form of language inadequacy and cognition building. Thus, classroom pedagogy in some contexts require re-aligning. Yet, when language pedagogy lecturers are given the responsibility to teach writing to Engineering and Technology students, there is a gap in terms of content matter because language lecturers are not Engineering content experts. As such, the question of how we as language 
practitioners can access Engineering and Technology students' thinking of substantive content as it relates to writing, is at the heart of this study.

\subsection{Marginalia and the Electronic Shift}

One way in which this idea of writing and thinking can come together is through the use of marginalia. Marginalia has existed from the time writing and printing were made possible. It is defined as notes written in the margins of texts and has been a main source of historical information for hundreds of years (Manguel, 1996). Marginalia is important for tracing both the reading and writing process of the person who apprehends text. In the 21 st century, marginalia, traditionally hand-written, has evolved into electronic versions. Electronic books use the concept of marginalia but call them annotations (Wagstaff, 2012).

The issue with the use of marginalia and its electronic shift is with how instructors and even students may not be immediately open to the idea. McKenna (2016) points out that in keeping with technological advancement, the teaching of reading and writing must make use of innovative ways of making sense of print. If marginalia and other reading tools were found in print form, they can also be transferred to electronic forms. McKenna (2016) also points out that the field of STEM has been more accepting of these changes. Thus, the application of electronic marginalia can be usefully applied for STEM students.

Microsoft Word has track-change function that allows the user to insert comments into texts. This is the most basic definition of electronic marginalia. Current literature on electronic marginalia shows that fairly little has been discussed, save for Edwards, Goodwin, O'Connor, and Phoenix (2017) who explain that marginalia and technology can be difficult to implement because "calling up electronic note functions and inserting them into online text is impersonal" (Edwards et al., 2017, p. 162). However, in this current study, the research participants will be communicating their thoughts with their respective lecturers. This current study sets out to explore the potential of using electronic marginalia.

\section{Research context}

As part of the Scholarship of Teaching Learning (SoTL) initiative, this project was underpinned by principles of action research. Action research assumes that researchers who are themselves teachers/lecturers in the class will carry out an intervention within a research cycle, usually understood as one semester or academic year.

For this study, the research cycle was designed to occur within a 14-week academic semester of first year undergraduates from the Engineering, Technology, Geoscience and Applied Science faculties of a private university in Malaysia. The subject involved in this study was Academic Writing. Two groups of 25 first year undergraduates and two lecturers respectively were involved in this study.

Although Academic Writing has been taught in this university for very many semesters, both lecturers only began to systematically experiment with using electronic marginalia about two semesters prior to the semester described in this study. In this semester, we systematically crafted our respective classes to be conducted through the following format. In the first eight weeks of the semester, face-to-face lectures were carried out. These lectures addressed the fundamental building blocks of Academic Writing which are summarising and paraphrasing as well as citing and referencing. In the remaining six weeks, the lectures were replaced with multiple draft-writing which was done by the individual student. At this point, the students no longer met as a class, but met with the lecturers on a consultative, one-to-one basis. Emails were used as the means by which the 
softcopy drafts were sent. During these consultation sessions, students receive feedback, continue drafting, receive more feedback and finalise their essay. It is important to note that drafting process in previous semesters involved the use of hard-copy drafts which were submitted drafted using Microsoft Word and then printed and submitted by students. However, lecturers' feedback was handwritten on those printed copies. Often, those feedbacks were brief so as only to flag up the categorical nature of the error. For example, an orthographical error will be represented by "sp" to indicate a spelling error. Little to no further explanations will be given. It was assumed that further explanations will be given during the one-on-one consultation. In this study, however, feedbacks given in the electronic marginalia were done in greater detail. Particularly, there was greater propensity for the lecturers to provide error feedback not just in the categorical sense but through a communicative manner.

\section{Findings}

Findings of the study are presented through two sub-sections; one sub-section is derived from the lecturers' perspective and while the other is from the students' perspective.

\subsection{Lecturers' perspectives}

Data from lecturers' perspective is drawn from their reflections, observations and on-going discussions. Although the use of technology in the process of drafting was relatively new in its application, both lecturers found that the use of e-marginalia allowed for corrective feedback to be given to the students in a more systematic way. There were three points that illustrated why the lecturers considered the exercise to be significant. The key points are convenience, tracking ability and relationship-building.

First, both lecturers noted in their reflections that providing feedback using Microsoft's track change infrastructure was a convenient means of guiding the students with their draft writing. This was because all drafts were kept in softcopy version and all feedbacks were located in these softcopy forms. What this meant was the lecturers were not bogged down by hardcopy prints. In an increasingly seamless environment where professional and personal lives co-exist, the lecturers could easily bring their work along with them through a USB port. As long as they had a word processor, they could work on providing timely feedbacks to their students even and especially when they were away from their institution.

Second, both lecturers found Microsoft's tracking ability to be crucial in building a coherent narrative of feedback. This was because Microsoft's track change function provides time stem in terms of the dates in which the comments were made. What made the process systematic was how the corrective feedback was built in a cumulative sense. This is because the corrective feedback process visually occurs on the 'same' sustained platform that captures the lecturer-student communication from the beginning until the end of the draft writing process. Figure 1 illustrates the dates and hierarchical fashion of the dialogue that takes place within the margins of word document. For purposes of confidentiality, the names of the lecturer and student have been removed. The dialogue here can be differentiated according to the colours of the author icon. 


Is biofuel a suitable alternative source to replace fossil fuel as source of energy in
transportation?
Introduction
\[ \begin{array}{l}\text { According to the World Energy Council, about } 82 \% \text { of the world's energy needs are } \\ \text { currently covered by fossil resources such as petroleum, natural gas and coal (Soetaert, 2009). This } \\ \text { shows that since the Revolution Industry started in the } 18^{\text {th }} \text { century, the demand for an ideal source }\end{array} \]

Fig. 1. Dates and hierarchical fashion of dialogue in e-marginalia

Third, the lecturers found that the infrastructure of e-marginalia became a bridge that facilitated in student-lecturer relationship-building. This was because the lecturers could provide communicative feedback through the language functions of questioning, clarifying, affirming and encouraging. The lecturers found that because they were comfortable and more importantly, skilled at using the keyboard to type their queries and comments, the technology afforded by Microsoft Word could optimally facilitate their process of communicating with the students via the electronic medium. Because the lecturers used these language functions in the marginalia, students also modelled after the lecturers and equally responded with language functions of questioning, confirming and informing.

\subsection{Students' perspectives}

All 50 students in this study organised their draft writing according to the lecturers' requirements. However, the students were differently meticulous with their drafting process. Some were more systematic than others. After the semester ended, the students were asked about their experience of draft writing using electronic marginalia. It is important to note that their response about the use of e-marginalia is with reference to and contrast with their other experience of using Microsoft word for other projects and assignments. All 50 students informed that they had up until then, not been asked to use the track change function for any other project or assignment. The students' responses were gauged through an open-ended questionnaire and semi-structured interviews. This section discusses their emergent response from both research methods. Specifically, their response revolved around three points - ease of technology, detailed feedback and association with social media.

First, all the students who responded to the open-ended questionnaire cited the ease of use and convenience of utilising e-marginalia for their drafting process. Because of their basic ability with using Microsoft Word, the students found the track change function to be relatively easy to handle. Once they could use the technology, they benefitted from its convenience. The sense of convenience stemmed from the elimination of paper printing, being able to type their questions into the softcopy draft and being able to email the drafts to the lecturers without having to walk across the campus to submit hardcopies. They found this to be time-saving.

Second, all the students' response in the open-ended questionnaire indicate that they found the combination of softcopy submissions and one-on-one consultations to be well organised in terms of how they could already view the lecturers' feedback even before they turned up for the face-to-face consultation. The communication and exchange that took place during the face-to-face sessions were important for how the students could clarify the error 
feedback with the lecturers. This meant that students received detailed and clarified feedback so that they could continue to work on the following draft. The students also felt that the face-to-face component of the draft writing process was crucial to the overall experience of writing. The detailed nature of the received feedback was shaped by the relationship built especially during the consultation sessions. Although written feedback was documented through e-marginalia and could be sent via email, the students overwhelmingly stated that they still required the face-to-face component of the drafting process. This points to the importance of human relationship formation in the pedagogical context.

Third, during a semi-structured interview, one student elaborated that he found the use of emarginalia to be positive because it reminded him of the communications and exchanges he encounters in social platforms like Facebook ${ }^{\circledR}$ and WhatsApp ${ }^{\circledR}$. Coming from a generation that is comfortable with dialoguing through speech bubbles, this student was pleasantly surprised by how the draft writing process through e-marginalia resembled his social exchanges with his friends through social media. He eased into this process very quickly and was able to carry out the language functions of questioning, clarifying and explaining in order to improve his draft. Figure 2 below is an example of this student's e-marginalia exchange with the lecturer. The layout of speech bubbles on the right side of the page, juxtaposed with the Academic Writing genre on the left side of the page illustrates how two seemingly incompatible worlds can come together to advance technical knowledge and improve writing skills.

\begin{tabular}{|c|c|}
\hline \multirow{3}{*}{$\begin{array}{l}\text { One of the redesinged process which is highly recommended to replace the current waste } \\
\text { management technique is Integrated Solid Waste Management. As society becomes more } \\
\text { advanced, simple solutions are no longer sufficient to solve the ever-growing SWM disposal } \\
\text { problems. Besides, there is no single treatment system which is generally appropriate for all } \\
\text { waste fractions (Menikpura. Sang-Arun, and Bengtsson, 2013). Therefore, the combining of } \\
\text { appropriate treatment methods such as recycling, anaerobic digestion, incineration, landfilling, } \\
\text { etc. are required for proper, balanced SWM management (Menikpura, Sang-Arun, and } \\
\text { Bengtsson. 2013). This approach is known as integrated solid waste management (ISWM) which }\end{array}$} & $\begin{array}{l}\text { November 17, } 2017 \\
\text { In a sentence before this, explain how this ISWM is } \\
\text { related to the two methods before. State that this is a } \\
\text { new method which you will now discuss. }\end{array}$ \\
\hline & $\begin{array}{l}\text { November } 22,2017 \\
\text { This ISWM is not related to the current } \\
\text { techniques but it is a new technique. Is my first } \\
\text { sentence good enough, or should I add } 20 \text { ? }\end{array}$ \\
\hline & \\
\hline
\end{tabular}

Fig. 2. Juxtaposition of speech bubbles and Academic Writing genre

\section{Analysis and implications of findings}

Findings from this study were drawn from the students and lecturers involved in the use of e-marginalia within one semester of Academic Writing. The emergent themes are convenience, tracking ability, relationship-building, ease of technology, detailed feedback and social media. Emergent themes (as discussed in the section above) can be further analysed and understood in relation to overarching categories (Saldaña, 2013). Therefore, from six emergent themes, four emergent categories are proposed as overarching notions that can be abstracted from the data. The four emergent categories therefore, are lifestyle norms, organization norms, technological norms and social norms. Here, the use of 'norms' is significant for how it can account for the habituation process that takes place during the teaching and learning environment. This is because the habituation process forms the foundation of human culture and behaviour. Thus in understanding how the lecturers' and students' feedback is located within human culture and behaviour, we can better appropriate modern teaching and learning methods in our ever-changing classrooms. Table 1 presents emergent themes and corresponding categories. 
Table 1. Emergent themes drawn from the participants of this study

\begin{tabular}{|c|c|c|}
\hline Study participants & Emergent themes & Emergent categories \\
\hline \multirow{3}{*}{ Lecturers } & Convenience & \multirow{6}{*}{$\begin{array}{l}\text { Lifestyle norms } \\
\text { Organization norms } \\
\text { Technological norms } \\
\text { Social norms }\end{array}$} \\
\hline & Tracking ability & \\
\hline & Relationship-building & \\
\hline \multirow{3}{*}{ Students } & Ease of technology & \\
\hline & Detailed feedback & \\
\hline & Social media & \\
\hline
\end{tabular}

Findings from this study suggests that even as technological infrastructure expands at remarkable speeds, the application of such infrastructures are experienced in relation to lifestyle and organization norms of those involved in the pedagogical process. Students for example will locate the technological infrastructure within the ambit of what they consider to be acceptable in their day-to-day lives. This is what Miller (2010) refers to as the complexities of human-material relationship where focus should be placed not on the 'stuff' of technology, but the appropriation of stuff through human enculturation. Thus, it is important to understand young people's cultural acceptance especially when engineering educators pledge to locate students at the centre of the pedagogical process.

Further, the question of how language practitioners can access students' thinking of substantive content as it relates to writing can be addressed through the appropriation of technology with technological norms. This refers to the intangible but powerful cultural practice of lecturers and students with regard to their levels of acceptance of technological change (McKenna, 2016). For example, lecturers who are skilled and up-to-date with technological change will find themselves more amenable to new norms of imparting knowledge and skill through the medium of technology (McKenna, Labbo, Kieffer, \& Reinking, 2012). In line with McKenna's (2016) contention that the field of STEM has been more accepting of these technological changes, this study encourages lecturers and students to be open to cultural changes as deep-seated human behaviour intersperse with modern technological advancement especially within the field of STEM.

Finally, underpinning these findings lies the role of social norms which form the foundation of human relationship. Even as technology progresses and democratises education and knowledge production, it is the human-social connection that is key to meaningful and valuable exchange (Chong, 2018). Insofar as the technological device can aid the teaching and learning process, the innovativeness of modern teaching methods is mediated by the strength of trust that is built within the student-lecturer relationship. Without this trust, any technological advancement in the 21 st century classroom will not be suitably appropriated.

Through the prism of human culture and behaviour, we understand that technological infrastructure can be better capitalised through the cultural appropriation of sustaining human relationships with technological content. 


\section{Concluding remarks}

In confronting the modern educational framework through Education 4.0, educators and policy makers must be prepared for the tension resulting from the intersections that occur when technological infrastructure connects with human culture. Minutiae data from this study suggest that the endeavour of teaching and learning in a subject like Academic Writing is still in need of the communicative, face-to-face connection of human exchange. Particularly, technological advancement must be matched with sociocultural norms of those involved in the educational process. Perhaps to the ultimate question of whether technology will supersede human connection, it appears that human communication is still valued.

This study is funded by Universiti Teknologi PETRONAS' Scholarship of Teaching and Leaning (SoTL) grant (0152AA-A52). We are most grateful to UTP's Centre of Excellence for Teaching and Learning (CeTAL) for the support.

\section{References}

Bromley, P., Meyer, J. M., \& Ramirez, F. O. (2011). Student-Centeredness in Social Science Textbooks, 1970-2008: A Cross-National Study. Social Forces, 90(2), 547-570.

Chong, S. L. (2017). Student-centredness in Engineering Education: Where goes the teacher? . Paper presented at the 7TH World Engineering Education Forum (WEEF) 2017 (14th - 16th November, Berjaya Hotel, Kuala Lumpur, Malaysia.

Chong, S. L. (2018, 22nd February). Of technology, time and the 21st century, Opinion, New Straits Times. Retrieved from https://www.nst.com.my/opinion/columnists/2018/02/337817/technology-timeand-21st-century

Clements, D. H., \& Sarama, J. (2016). Math, science and technology in the early grades. The future of children, 26(2), 75-94.

Committee on the Engineer of 2020 National Academy of Engineering. (2005). Educating the Engineer of 2020 : Adapting Engineering Education to the New Century. . Washington: National Academies Press.

Dejarnette, N. K. (2012). America's children: Providing early exposure to STEM (Science, Technology, Engineering and Math) Initiatives. Education, 133 (1), 77-84.

Edwards, R., Goodwin, J., O'Connor, H., \& Phoenix, A. (Eds.). (2017). Working with paradata, marginalia and fieldnotes. Cheltenham, UK: Edward Elgar.

Felder, R. M. (2011). Engineering education: A tale of two paradigms. In B. McCabe, M. Pantazidou \& D. Phillips (Eds.), Shaking the foundations of Geo-engineering education (pp. 9-14). Leiden: CRC Press.

Jenkins, S., Jordan, M. K., \& Weiland, P. O. (1993). The Role of Writing in Graduate Engineering Education: A Survey ofFaculty Beliefs and Practices. English for Specific Purposes, 12, 51-67.

Manguel, A. (1996). A history of reading. London: HarperCollins.

Mascolo, M. F. (2009). Beyond Student-Centered and Teacher-Centered Pedagogy: Teaching and Learning as Guided Participation. Pedagogy and the Human Sciences, 1(1), 3-27.

McKenna, M. C. (2016). Literacy instruction in the brave new world of technology. The Phi Delta Kappan, 96(3), 8-13.

McKenna, M. C., Labbo, L. D., Kieffer, R. D., \& Reinking, D. (Eds.). (2012). International Handbook of Literacy and Technology (Vol. 2). London: Routledge.

Miller, D. (2010). Stuff. Cambridge, UK: Polity Press. 
Pretz, K. (2016). A Look at the State of Engineering Education Worldwide. The Institute: The IEEE news source.

Saldaña, J. (2013). The coding manual for qualitative researchers (2nd ed.). London: SAGE.

Wagstaff, L. K. (2012). The Evolution of Marginalia. Retrieved 5 January 2017, from http://www.wkiri.com/slis/wagstaff-libr200-marginalia-1col.pdf 